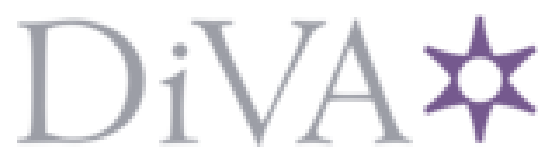

http://www.diva-portal.org

\title{
Postprint
}

This is the accepted version of a paper presented at IE2014, 2-3 December 2014, Newcastle, Australia.

Citation for the original published paper:

Mustaquim, M., Nyström, T. (2014)

Video Game Control Dimensionality Analysis.

In: Blackmore, K., Nesbitt, K., and Smith, S.P. (ed.), Proceedings of the 2014 Conference on

Interactive Entertainment (IE2014) New York: Association for Computing Machinery (ACM)

http://dx.doi.org/10.1145/2677758.2677784

N.B. When citing this work, cite the original published paper.

Permanent link to this version:

http://urn.kb.se/resolve?urn=urn:nbn:se:uu:diva-234183 


\section{Video Game Control Dimensionality Analysis}

Moyen M. Mustaquim

\author{
Uppsala University \\ Uppsala, Sweden \\ +46 (0) 703335146 \\ moyen.mustaquim@im.uu.se
}

Tobias Nyström

\author{
Uppsala University \\ Uppsala, Sweden \\ +46184715149 \\ tobias.nystrom@im.uu.se
}

\begin{abstract}
In this paper we have studied the video games control dimensionality and its effects on the traditional way of interpreting difficulty and familiarity in games. This paper presents the findings in which we have studied the Xbox 360 console's games control dimensionality. Multivariate statistical operations were performed on the collected data from 83 different games of Xbox 360. It was found that the player's perceived level of familiarity and difficulty can be influenced by the game control dimensionality. We also found that the perceived difficulty varies with control dimensionality and that the familiarity tends to show no relation to the user's perceived difficulty. A way to measure and better understand familiarity and difficulty for games using the control dimensionality can thus give a better interpretation of different genres of games to its players and also to the game designers for further improvements in games' design. Positive transfer of this could bring forward new knowledge for game designers to augment learning of different genres of games.
\end{abstract}

\section{Categories and Subject Descriptors}

K.8.0. [Personal Computing]: General - Games.

\section{General Terms}

Experimentation

\section{Keywords}

Game control; Video games; Control dimensionality; Game controller; Learning games.

\section{INTRODUCTION}

Historically a critical and important aspect of a game is the game controller-hardware with which a player interacts most of the time during play. Thus a controller has always been one of the major challenges in console and game design since players spend many hours in learning to efficiently use the buttons of a controller before they are able to master it [18]. Therefore the design of video games control has much importance. It is interesting to

"Copyright is held by the owner/author(s), 2014. Publication rights licensed to ACM. This is the author's version of the work. It is posted here by permission of ACM for your personal use. Not for redistribution. The definitive version was published in IE2014, December 02-03 2014, Newcastle, NSW, Australia http://dx.doi.org/10.1145/2677758.2677784 ". notice that very few studies have concretely examined the effect of game controllers on game enjoyment [25]. A successfully designed controller can contribute in identifying different player experiences by defining various types of games that have been effortlessly played with a controller because of the controller's design [18]. One example is the Microsoft Xbox controller that became a favorite among players when playing "first personshooter" games because of its shoulder triggers, which contributed to the success of the popular game Halo on Xbox [18, 28]. One major issue of the controller is that the complexity of control is a function of the number and type of available inputs [27]. This also includes the complexity in the mapping of different buttons relating to the game for perusing different actions. In this paper we have presented the study results of video games control complexity analysis for Xbox 360 console games. The underlying research question behind this paper's research was: How do video games control complexities have impacts on the traditional understanding of both difficulty and familiarity in Xbox 360 console games? The analysis of coded data for different games control dimensionality provides a new insight into understanding the difficulty and familiarity in gaming. Our results have shown how we may take a different look into understanding the difficulty and familiarity parameters based on the control dimensionality. These understandings are essential for further research ideas that have been initiated in this paper. The paper is divided into six sections. After this introduction, Section 2 gives a brief background to the video games controller, its complexity, together with familiarity and difficulty in gaming. Section 3 describes our methodology for conducting the research. Section 4 and its subsections present the different results that we have found. Sections 5 and 6 give discussions and future research. Finally, a conclusion is taken in Section 7.

\section{BACKGROUND}

A card game allows the user to have control by direct manipulation but video game systems demand an input device for control and the video game system's basic controls are directly related to its physical design [14]. Video game consoles like Microsoft's Xbox 360, Sony's PlayStation 3, and Nintendo's Wii $\mathrm{U}$ are sold with a proprietary controller (see Figure 1 below).

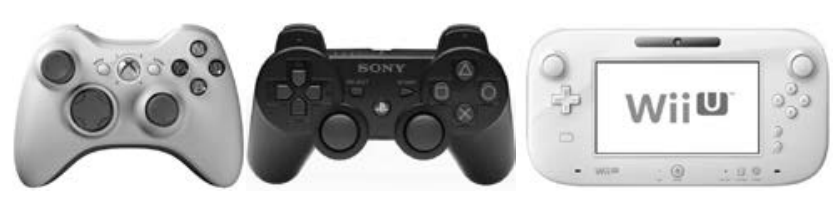

Figure 1: Xbox 360, PlayStation 3, and Wii U Controllers

The designs of the controller for Xbox 360 and PlayStation 3 are very similar, whereas Wii $U$ (and also the controller for its 
predecessor, Wii) is quite different. The video game controller has evolved over time and the functionality and complexity has increased from a single button joystick to today's multi-button and stick controllers. One of the first commercially successful joysticks was a digital joystick with a single firing button bundled with the Atari Video Computer System 2600 in 1977 [4]. The history of the joystick can be traced back to the 1920s when the first joystick was invented and developed at United States Naval Research Laboratory (NRL) [1]. In 1986 the first gamepad (also known as "joy pad") arrived with the Atari 7800 system, but it was with the Nintendo Entertainment System (NES) that a gamepad was used to its full potential and became a success [12]. The NES controller consisted of two buttons and a directional pad (D-pad). Nintendo had designed the "cross"' design on the D-pad for its handheld Game \& Watch games in the early 1980s. The first video game console to be equipped with analog control was the Nintendo 64. This controller included an analog stick with a small joystick-like device that enabled players to provide a vector as a directional input [12], i.e. more force on the stick in one direction gave a certain response into some games. Another development and feature integrated into the game controller was the haptic feed (also known as "force feedback") e.g. the controller can shake during game play as a response to certain actions, as if you had driven a car off the road, and also analog buttons are used, which sense and register how hard a button is pressed [12]. One of the latest developments is to add motion control to the game controller. For example, Nintendo Wii uses several accelerometers to register motions that the player makes with the controller [12]. Also the handheld game controller could be supplemented or replaced with motion sensors in a camera that tracks the action motions of the player, e.g. Xbox Kinetic for Xbox 360. Sony developed something similar with their PlayStation Move, for which special handheld controllers are tracked with a camera. However, one type of game control system is not better when compared to others. Instead, what counts is whether or not the game control system is well suited for the game experience [14]. The game control dimensionality can be measured, evaluated, and benchmarked using different metrics. One potential problem that video game controllers might experience is a lack of natural mapping depending on whether the controller conforms and is able to complete the player's mental model, i.e. cognitive representations of situations in real or imagined worlds. Natural mapping takes advantage of physical analogies and cultural values giving an instant fundamental understanding [22]. One example to bridge this problem has been seen in arcade games, which traditionally have included realistic controllers that correspond to real-life modes of vehicle operation, such as handlebars, wheels, and flight sticks [25], something mimicked in video games, e.g. Wii Wheel with which a wheellike controller used with games on the Wii game console. Previous experimentation has found that when comparing different game controllers, players have had higher play experience with better natural mapping of the controller, although they perform worse in a game compared to a less natural mapped controller, i.e. a racing wheel controller compared to the classic Xbox controller [19, 20]. Although more enhanced gaming technology, like better graphics and more realistic controls, might enhance enjoyment, technological advances per se do not automatically give a more positive response [17]. For example, Brown and Cairns [9] have found that game control related to access constitutes a foundation for reaching engagement with the game. Feedback from the controller needs to correspond in an appropriate way and thus enable the player to reach expertise at least at the main controls [9]. One player who participated in Brown and Cairns' research said, "You just press anything just to try and kick, you don't really know what the controls are” [9] which shows the problem that could arise with the game controller, especially if it is equipped with many buttons and pads to choose from. A natural progress (the learning curve) exists in the process that starts from learning the game controls by trial and error towards reaching automation of control and movement'mastery of controls' [10]. However, the time to reach it depends on the controller design used in the game. An important factor in designing controllers is the capability of the controller to be used with many different types of games [12]. For example, a steering wheel could be good and might increase the player's experience in certain games yet might be more or less worthless as a controller in other types of games. Another example is the 'fishing-rod controller' used together with fishing games. In video games, the success of control is consequently restricted to the design of the game control scheme and the physical controller, e.g. the Xbox 360 player has to press a button, move one of the sticks or D-pad in a certain way or combination to open the door in a video game. What is important is that when the players use game controllers, a basic form of natural mapping exists. For example, moving the stick downwards gives a 'backward' movement and a movement to the right of the stick gives a movement to 'right'. If the basic form of natural mapping is lacking, it will result in frustration and confusion. Then the game experience will also be negatively provoked. This will damage the enjoyment with the game since it will counteract existing mental models [25]. Previous research has found that different controllers (gamepad, Xbox Kinetic, and Sony Move) mediate gameplay experience, perceived both for personality and satisfaction of need [6].

The metrics considered in this paper are 'control dimensionality' and 'difficulty and familiarity in the video games', for assessing the complexity of the games controller and to analyze its relationship with difficulty and familiarity.

\subsection{Control Dimensionality}

The player experience is dependent on a good video game control scheme, since it is the control interface between the player and the video game system [27]. Control dimensionality (CD) developed by Activision Central Design Group is a measure of the degree of complexity inherent in a control mechanism [5]. CD can be used to evaluate and compare games and can give a candid assessment of the game's control specification [27]. In general, game designers should aim for as few controls as possible for core gameplay. Even though game developers are working on reducing controls down to an absolute minimum, one of the most common complaints from play testers and reviewers concerns difficulty of controls [26]. More advanced and complex game controllers will probably have more difficulty to fit all sticks and buttons in existing mental models and would probably also increase the time to become proficient since the learning will take longer. Research by Limperos et al. [17] indicated that game enjoyment was higher with a less advanced controller for PlayStation 2, compared with the more advanced Wii controller when participants played the same game, although the results might have been due to the specific game tested having been designed for a classic game controller like PlayStation 2.

Activision uses a two-step method to calculate CD for a game title. These steps are as follows [27]: 
Step 1: Determine basic movement scheme by choosing one of the following:

One dimension movement (left-right) $\mathrm{CD}=1$

Two dimensions movement (left-right, up-down) $\mathrm{CD}=2$

Three dimensions movement (left-right, up-down, in-out) CD = 3

Step 2: Add to CD for each secondary dimension of control. Here are some examples of secondary dimensions:

+1 : For each additional movement dimension, such as strafe backforth, accelerate-brake, rewind or fast-forward time, etc. this is typically achieved with two buttons.

+0.5: For each embedded action, such as jump, attack, rotate, etc. this is typically achieved with one button. An example of CD ratings on two different types of games is shown in Table 1.

The calculation of CD can give bias since it involves subjectivity. This bias should not be a problem and may be avoided if the subjective rules are consistently utilized during calculation of the CD [5].

Table 1: Example of control dimensionality ratings (from [26])

\begin{tabular}{|c|c|}
\hline Tetris, CD $=1.5$ & Half-Life, CD = 7 \\
\hline Calculated as: & Calculated as: movement in 2 \\
movement in 1 & dimensions (left-right, in-out) + \\
dimension + 0.5 for the & view in 2 dimensions (left-right, \\
embedded action rotate & up-down) + 0.5 for shooting, + 0.5 \\
& for jumping, + 0.5 for ducking, + \\
& 0.5 for weapon change, +1 for \\
& swimming. \\
& Note that there are minor \\
& additional control options that have \\
& been subjectively ignored. \\
\hline
\end{tabular}

Figure 2 shows the maximum CD for controllers on video game consoles, starting with the Atari 2600. The Atari 2600 has a joystick $(+2)$ and one button $(+0.25)$. Microsoft's Xbox 360 is equipped with a modern controller that has two joysticks $(+4)$ plus ten buttons (not considering the back and start buttons) [27]. This figure also shows how controller complexity has steadily increased over time. It will be interesting to see if this trend continues with future video game consoles. Designers may choose to add more complexity by doubling or tripling buttons, or they may choose to use fewer [27].

Table 2 shows the CD for individual games that were developed by Activision and illustrates the strength of this measurement. It becomes easy for game developers to understand the impact of a game controller scheme by comparing it to schemes of other games in the same genre. If a game has a significant positive difference in $\mathrm{CD}$ when compared to other games of the same genre, then it could have a problem in becoming successful since players will have higher difficulty in learning. On the other hand, if the difference is significantly negative then players might feel less challenge, even though the learning could be much easier.

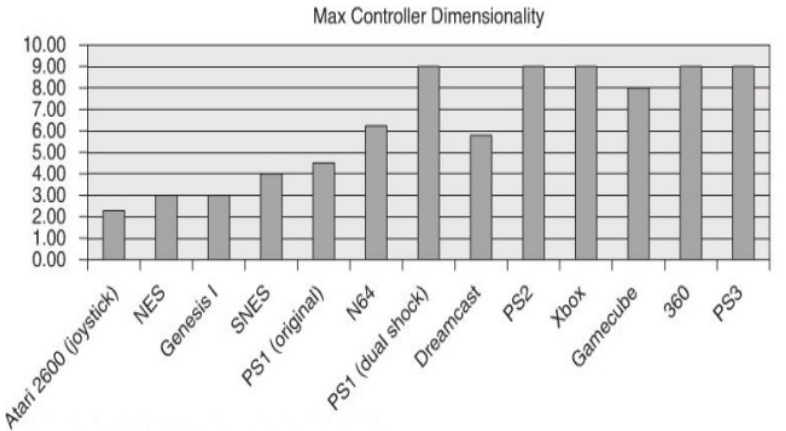

Figure 2: Maximum control dimensionality for different video game consoles (from [27])

Table 2: Control dimensionality for different video games (from [27])

\begin{tabular}{|c|c|c|c|c|}
\hline $\begin{array}{l}\text { Risk Factor } \\
\text { with Control } \\
\text { Scheme }\end{array}$ & Title & $\begin{array}{l}\text { Control } \\
\text { Dimensionality }\end{array}$ & Genre & $\begin{array}{l}\text { Differential } \\
\text { from Competing } \\
\text { Products in } \\
\text { Genre (in } \\
\text { Standard } \\
\text { Deviations) }\end{array}$ \\
\hline High-risk & $\begin{array}{l}\text { Marvel Uitimate } \\
\text { Alfiance }\end{array}$ & 7.75 & Brawler & +2.05 \\
\hline High-risk & X-Men:Legends II & 7.5 & Brawler & +1.83 \\
\hline High-risk & Gun & 8.5 & $\begin{array}{l}\text { 3rd Person } \\
\text { Shooter }\end{array}$ & .59 \\
\hline High-risk & $\begin{array}{l}\text { True Crime 2 } \\
\text { (shooting) }\end{array}$ & 8.5 & $\begin{array}{l}\text { 3rd Person } \\
\text { Shooter }\end{array}$ & +1.59 \\
\hline High-risk & $\begin{array}{l}\text { True Crime 2 } \\
\text { (fighting) }\end{array}$ & 7 & Brawler & +1.4 \\
\hline High-risk & $\begin{array}{l}\text { Call of Duty 2: Big Red } \\
\text { One }\end{array}$ & 8 & $\begin{array}{l}\text { 1st Person } \\
\text { Shooter }\end{array}$ & +1.2 \\
\hline High-risk & Spider-Man 3 & 6.75 & Brawler & +1.18 \\
\hline High-risk & $\begin{array}{l}\text { X-Men:The Official } \\
\text { Game (Nightcrawler) }\end{array}$ & 6.75 & Brawler & +1.18 \\
\hline Neutral & True Crime 2 (driving) & 4 & $\begin{array}{l}\text { Driving } \\
\text { Combat }\end{array}$ & +0.76 \\
\hline Neutral & Transformers (robot) & 6.25 & Brawler & +0.75 \\
\hline Neutral & Uitimate Spider-Man & 6.25 & Brawler & +0.75 \\
\hline Neutral & $\begin{array}{l}\text { X-Men:The Official } \\
\text { Game (Wolverine) }\end{array}$ & 6.25 & Brawler & +0.75 \\
\hline Neutral & Guitar Hero 2 & 3 & Arcade & +0.64 \\
\hline Neutral & Madagascar & 5.75 & Platform & +0.36 \\
\hline Neutral & $\begin{array}{l}\text { Transformers } \\
\text { (driving) }\end{array}$ & 3.5 & $\begin{array}{l}\text { Driving } \\
\text { Combat }\end{array}$ & +0.22 \\
\hline Neutral & Quake 4 & 7.25 & $\begin{array}{l}\text { 1st Person } \\
\text { Shooter }\end{array}$ & -0.19 \\
\hline Neutral & Shrek 3 & 4.25 & Brawler & -0.99 \\
\hline Low Risk & Call of Duty 2 & 6.75 & $\begin{array}{l}\text { 1st Person } \\
\text { Shooter }\end{array}$ & -1.11 \\
\hline Low Risk & Call of Duty 3 & 6.75 & $\begin{array}{l}\text { 1st Person } \\
\text { Shooter }\end{array}$ & $-1,11$ \\
\hline
\end{tabular}

\subsection{Difficulty and Familiarity in Games}

One of the important elements of a good game design is the issue of how to tackle the games to be difficult enough so that the players can feel enough challenges [3]. Measuring difficulty is thus a fundamental part of game design [2, 3, 8]. However, no precise definition of difficulty for games can be found and neither do the proper methodology or tools to measure difficulty exist [3]. Games presented in today's market lack dynamic game-balancing factors and often the traditional 'easy-medium-hard' description of difficulty measurement is followed [29]. Thus if we ask a player to determine the difficulty level of a game, the players usually use the concept of adaptivity and absolute difficulty to express their view on the difficultly level. Players may feel a game is less difficult if it offers them a continuous challenge with a constant level of tension without hampering their progress. On the other hand, the player may be considering a game to be more difficult if it requires any intrinsic skill and it is stressful to be successful in playing. However, although the CD is measured with an aim to keep its value within a certain limit to reduce the 
complexity in game playing, no evidence of user-perceived difficulty compared with CD is available today. Since scaling of difficulty is important and many previous studies in psychology and game design have shown that a lot more can be done during the design of the difficulty slope of the games (see $[2,3,15,16]$ ). It is thus worth investigating how the CD of the video games controller leaves an impact on measuring the difficulty of games. A factor that directly influences the level of difficulty is the challenge that players feel during the game play. Since active and motivated players are a key for designing successful games [21], a well-balanced challenge could bring the game closer to achieving this.

Familiarity has a powerful influence towards the building of positive gaming experience, although little research has been conducted for improving this factor in game design. A challenge may be classified as a composite factor associated with the cognitive, physical, and affective parts of a person [13, 24]. Thus challenges can be analyzed in different ways. In this respect, one of the factors to measure the challenge in making it suitable for an activity is familiarity [24]. Familiarity with the traditional way of thinking in game playing can be from remembering the certain scenarios or landmarks of the game environment, becoming useful in tackling the problems of similar genres of games. Research from Qin, Rau, and Salvendy showed that familiarity with a game can influence players' immersion into the story [23]. Also Cox et al. [11] found that challenge cannot be considered in seclusion but rather needs to be analyzed in relation to the player's expertise. It was also noted in research that when attempting to reach immersion through a balance of skill and challenge, the possibility of balance between skill and challenge must first be perceived by the players before immersion may be reached [11]. Familiarity is therefore one of the primary properties of a game which can make a game something easy to learn [7].

Over time players thus become familiar with many challenges that they perform regularly. Our hypothesis was that a familiarity factor will strongly influence the way in which a player perceives the difficulty of a game, in that more familiarity will tend to show less difficulty and vice versa. Relating to the discussion of CD, we have assumed that if it were higher for a game, then it should be superficially seen as more difficult by the player, since according to the perception of $\mathrm{CD}$ a higher value of it would imply higher complexity and apparent difficulty. At the same time, linking to familiarity, we have assumed that if players were familiar with a particular game or genre of game, then they would be surmised as able to propose a lower difficulty ranking for that game, i.e. familiarity and difficulty should be related, and if that is the case, then these two factors will be related to CD too. We have evaluated our hypothesis empirically, by coding the CD of Xbox 360 games. We have also analyzed the user-perceived difficulty and familiarity of each game that we have coded to measure the CD. The following sections outline and present these measures and findings.

\section{METHOD}

For this study we have coded 83 Xbox 360 games. We tried to select games based on their genres and tried to cover most of the common game genres possible. At first the numbers of degrees of movements were calculated. For instance, for a left and right operation, the CD was assigned to be 1 . For left-right, up-down operation the CD was assigned to be 2 and so on. Then the CD was increased for each secondary action. For each additional action or movement like accelerate and brake, bank left and right a +1 was added. If the actions were implemented with one button or combination of two buttons such as fire, jump, or duck, then a value of 0.5 was added. This was adopted from Activision where the measures were reflected as the degree of complexity that is essential in a control mechanism as addressed by Bateman and Boon [5].

For coding procedure, the controller buttons of Xbox 360 were been divided into three groups. Buttons $\mathrm{Y}, \mathrm{B}, \mathrm{A}, \mathrm{X}$ are titled as Face group. The Right Trigger, Right Bump, Left Trigger and Left Bump buttons are grouped as the Shoulder group of buttons. Right Stick, Right-stick press, D-pad, Left Stick, Left-stick press buttons are combined in the ASDP (analog stick and digital press) group of buttons. A group of students participated in the coding procedure. These students who agreed to participate in this study were spending on average about 5 to 6 hours per week in playing games. The students came to our game research lab where we have a set up with Xbox 360 console and different games. The procedure of $\mathrm{CD}$ calculation was explained to the volunteer participants. The students then coded the Xbox games that were available to them at home using the games manual. The students were also requested to answer two questions. In a scale from 1 to 9, they ranked their familiarity with each game they coded and the level of difficulty faced by them during play of that game. After receiving the result we double-checked the coding to remove any duplicate games data. It is important to mention here that, since the CD is static for individual games, it is therefore not participant-dependent. Our participants only volunteered for us for coding the games' CD. However the games that were coded by multiple students sometimes did not show the exact same controller dimensionality values. This is because of the misunderstanding of coding procedure by some students and therefore the values were different. We had to double-check this before we took the correct values for analysis. We then used SPSS version 19 to run statistical operation on the coded data. The results are shown in Section 4.

\section{RESULTS}

As mentioned in the method section, the button set of the Xbox 360 controller has been divided into three groups. We have selected Face as independent variable which holds the aggregated values of the buttons $\mathrm{Y}, \mathrm{B}, \mathrm{A}$, and $\mathrm{X}$. The variable Shoulder is independent and holds the aggregated values of Right Trigger, Right Bump, Left Trigger, Left Bump buttons. Also the independent variable ASDP holds the aggregated values of Right Stick, Right-Stick Press, D-pad, Left Stick and Left-stick press buttons. The following subsections describe different statistical operations on this data set and their results.

\subsection{Correlation Matrix}

We wanted to create a correlation matrix analysis to see how Face, Shoulder, ASDP, and complexity would be in regression with complexity as a dependent variable.

We ran a bivariate correlation option from the SPSS to find out the Pearson and Spearman results shown on Table 3. 
Table 3: Correlation Matrix

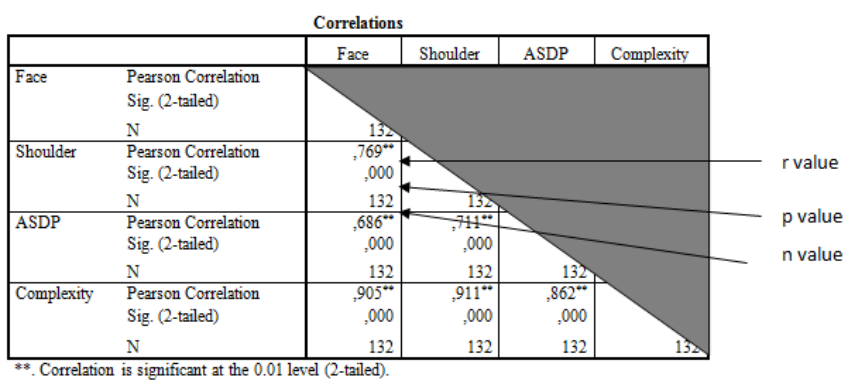

First, we ignored the information above the diagonal since it was redundant. The $r$ value indicates the strength and direction of the correlation. The $p$ value is the probability that we would see an $r$ value of this size just by chance. The smaller value of $\mathrm{p}$ was better. We could reject the null hypothesis $\mathrm{H}_{0}$, if $\mathrm{p}<=0.5$. Finally, the $\mathrm{n}$ indicates the number of pairs in sample. We calculated the degrees of freedom $D_{f}$ from $n$ using, $D_{f}=n-2$. Since the p value for all the variables were below .05, we could reject the null hypothesis which meant that we had a true relationship finding. No p value of any variable was higher than .05 , which would make it less confident that there was a correlation between those variables. Since $r$ value for complexity was higher, we could be more confident that a correlation existed. Hence, in a regression, complexity may work a dependent variable. Here we have rejected the null hypothesis, which means that we have evidence that we have found a true relation. The finding from this analysis can be explained as follows:

The research hypothesis was thus supported. Complexity correlates significantly with Face, $\mathrm{r}(130)=.905$, with Shoulder, $\mathrm{r}$ $(130)=.911$ and with ASDP, $r(130)=.862 . p \leq 0.5$. Degrees of freedom $\left(D_{f}\right)=n-2$, i.e. $D_{f}=132-2=130$.

We concluded with the decision that, in a regression, complexity can act as a dependent variable, whereas the Face, Shoulder, and ASDP variables will work as independent variables.

\subsection{Multiple Regressions}

The value of $r$ squared was found to be 0.979 , which is expressed as a percentage to be 97.9 . This means that 97.9 percent of the variance in the dependent variable complexity is explained by the model which includes the variables of Face, Shoulder, and ASDP. These three independent variables showed a satisfactory relation with the dependent variable complexity, as their value is above 0.3 . Also the value of each independent variable was less than 0.7 and therefore all these variables could be retained. Hence, these three independent variables correlated substantially with complexity. Again the beta value was highest for the Face variable. Therefore it made the strongest unique contribution to explaining the dependent variable complexity, while the variance was explained by all other variables in the model. The ASDP variable made comparatively less contribution in the model with a lower beta value. However, the Face and Shoulder variables were making significant unique contribution to the prediction of the dependent variable.

Since $\mathrm{p} \leq 0$ we rejected $\mathrm{H}_{0}$. It is worth mentioning that the $\mathrm{p}$ values for the independent variables were the same as seen on the correlation matrix. In this case our regression equation became as follows:

$\mathrm{y}=0.913(\mathrm{~b}) 1.101(\mathrm{c})+1.096(\mathrm{~d})+0.910$

where $y$ was the complexity and b, c, and d were any given values for the Face, Shoulder, and ASDP variables.

Table 4: Model summary table in multiple regressions

\begin{tabular}{|c|c|c|c|c|}
\hline Model & $\mathrm{R}$ & R Square & $\begin{array}{c}\text { Adjusted R } \\
\text { Square }\end{array}$ & $\begin{array}{c}\text { Std. Error of } \\
\text { the Estimate }\end{array}$ \\
\hline 1 & $.990^{\mathrm{a}}$ & .979 & .979 & 1.949 \\
\hline
\end{tabular}

\section{a. Predictors: (Constant), ASDP, Face, Shoulder \\ b. Dependent Variable: Complexity}

Thus we then could calculate the complexity of a game controller using this formula. Three scatter plots were drawn with the criterion value (complexity) on the y axis and three independent variables Face, Shoulder, and ASDP as predictors on $\mathrm{x}$ axis. These plots clearly showed correlation between the respective two factors on each plot. Figure 3 shows these three scatter plots.
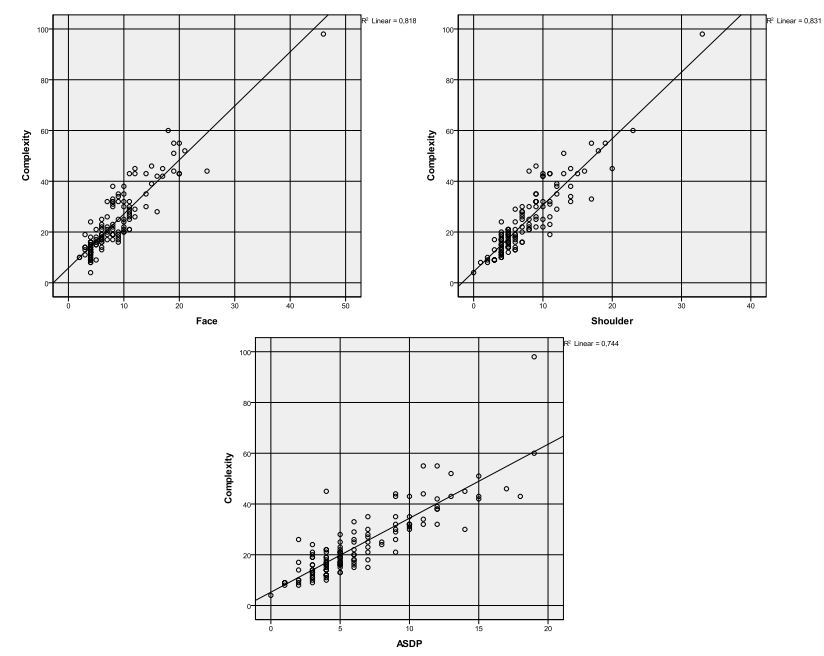

Figure 3: Scatter plots for complexity and three independent variables (Face, Shoulder, and ASDP)

\subsection{Relation Between Difficulty with Controller Complexity and Difficulty with} Familiarity

These two variables are not in a regression with familiarity, i.e. familiarity did not show a relation to complexity or difficulty in the existing data set. The scatter plots in Figure 4 (see below) clearly showed no relation between familiarity and difficulty or familiarity and complexity. 

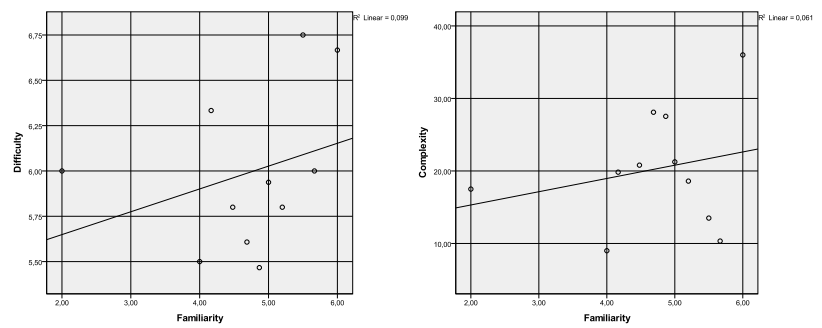

Figure 4: Scatter plots for difficulty and complexity versus familiarity variable

Figure 5 shows the line graph for difficulty and familiarity. The more familiar a player is with a game, the less difficulty that player is presumed to feel, but we did not see this kind of relation here. Sometimes lower familiarity gave lower difficulty and sometimes higher familiarity showed a higher level of difficulty. So in this data set, familiarity and difficulty showed no significant relation (also noticed from the scatter plots in Figure 3).

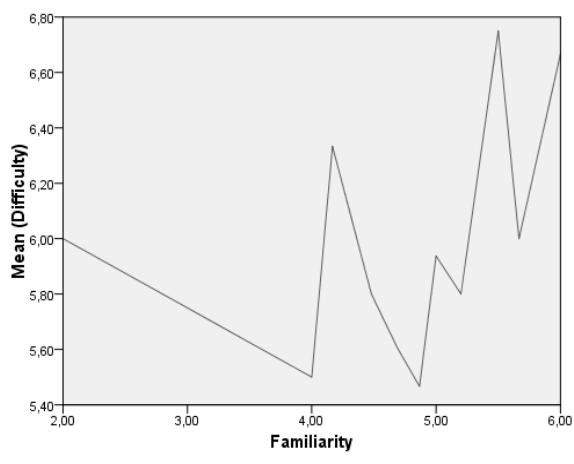

Figure 5: Line graph for user-perceived difficulty and familiarity

\subsection{T-test with Complexity and Difficulty Pair}

A paired sample t-test was conducted to evaluate the impact of the intervention on complexity and difficulty. The Sig value on the paired sample test table (Table 5) is below 0.05, which proved a significant difference between the two scores. From the paired sample statistics table it was noticed that complexity showed the highest score with the highest mean value. The effect size is calculated below, using one of the most commonly used effect size statistics called 'Eta squared', where the Eta squared values are interpreted as $.01=$ small effect, $.06=$ moderate effect, and .14 = large effect.

$$
\begin{aligned}
\text { Eta squared }= & \frac{\mathrm{t}^{2}}{\mathrm{t}^{2}+(N-1)} \\
& =\frac{5.908^{2}}{5.908^{2}+11-1}=0.77
\end{aligned}
$$

The Eta squared value obtained here is 0.77 , which proves that there is a large effect in the substantial difference between complexity and difficulty.
Table 5: Paired sample statistics in t-test

\begin{tabular}{|c|c|c|c|c|}
\hline & Mean & $\mathrm{N}$ & $\begin{array}{c}\text { Std. } \\
\text { Deviatio } \\
\mathrm{n}\end{array}$ & $\begin{array}{c}\text { Std. Error } \\
\text { Mean }\end{array}$ \\
\hline Pair 1 Complexity & 20.2225 & 11 & 8.03069 & 2.42134 \\
Difficulty & 5.9875 & 11 & .43456 & .13103 \\
\hline
\end{tabular}

However, familiarity and difficulty did not show any significant relation to complexity, as shown in Figures 6 and 7.

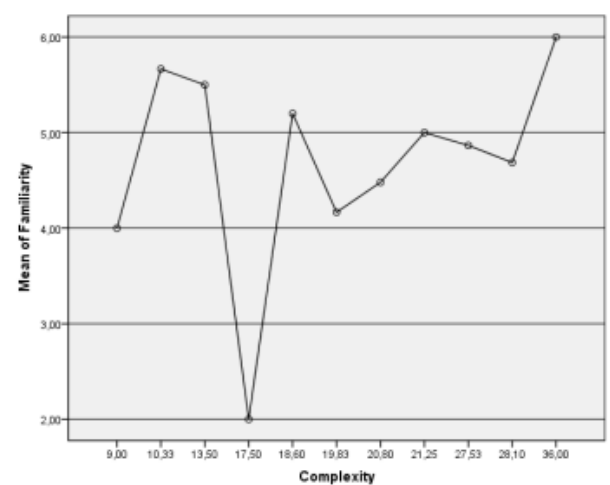

Figure 6: Mean plots of familiarity and complexity

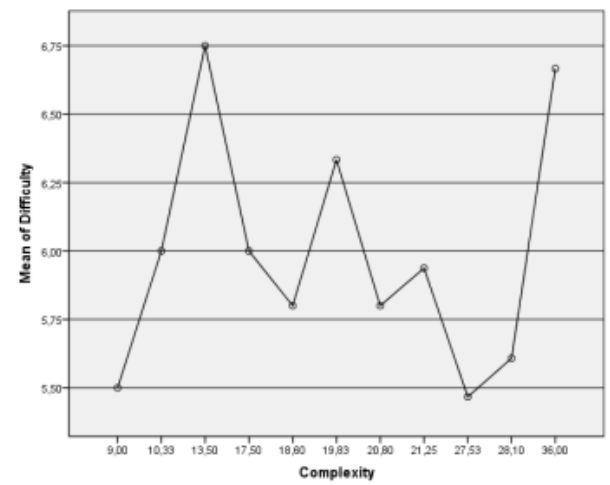

Figure 7: Mean plots of difficulty and complexity

\section{DISCUSSION}

We came to several interesting conclusions from our analysis presented in the results section, which will be discussed here. As mentioned earlier, our hypothesis was that a familiarity value that has been assigned by the players should be influenced by the CD value of each game and vice versa. Also the level of difficulty assigned by each player should depend on how familiar the players had become in playing that particular game or a game of that particular genre. There should also have been an influence of the complexity value on the difficulty. Our analysis showed that if players were familiar with a specific type of game genre, then they would not tend to feel less difficulty during the play of that type of game. So more familiarity with a particular genre does not mean less difficulty while playing other games of that same genre. Also, if the difficulty of a game were to become higher, naturally 
the complexity of the controller should be higher too or vice versa. Therefore, more familiarity would mean being familiar with the $\mathrm{CD}$ of the game controller. The perceived difficulty of a game would have a true relation to the complexity level, when the players might define their familiarity in a proper way, i.e. the familiarity factor consists of the complexity parameter. Thus players could feel less difficulty when playing a game if they were more familiar with the CD of that game and its genre. So a player who is familiar in playing a game of genre A should be familiar with playing a game of genre $B$ because the controller complexity of genres A and B are similar, even though there is no significant similarity between genres $\mathrm{A}$ and $\mathrm{B}$. The level of difficulty of two games can also be similar, based on not only the genre but also the complexity. So the difficulty perceived by the user can be defined as a 'better difficulty level' once it is measured with the user's knowledge of controller complexity. If players are familiar with some game genres that does not necessarily mean that they will feel less difficulty in playing another game from that genre. Nevertheless, since controller complexity differs from the user-perceived difficulty, complexity overrules the familiarity parameter. The familiarity variable will probably be in a regression with difficulty, if a value is added to it. That value can be derived from the CD. The familiarity parameter for a game can be therefore newly defined. If we are aware of the game controller complexity properly and may learn to play games accordingly, then we may define familiarity in a new way. Measuring the level of difficulty can then take a new shift while considering the dimensionality factor. It will be interesting to see these claims statistically proven to be in practice. Further research will investigate these matters.

The research question asked in the introduction section, (How do video games control complexities have impacts on the traditional understanding of difficulty and familiarity in Xbox 360 console games?) is therefore answered here. Video games' CD does have impacts on understanding familiarity and difficulty in Xbox 360 console games. These impacts are the result of considering $C D$ to find relations between familiarity and complexity and thereby revisiting their understanding. This can reduce the gap between theoretical and practical understanding of CD and two important parameters of game design that are addressed in this paper. This result can therefore take us back to the findings by Limperos et al. [17]. Their indication that a less advanced controller tends to increase game enjoyment can therefore be mapped in our findings. That is to say, higher CD tends to have a relative impact on difficulty and familiarity of games, which in return results in the game enjoyment in due course. However, this result cannot be generalizable to other video game platforms or other types of game controllers. Hence it is restricted within the boundaries of the specific Xbox 360 games and its controller, since our data set was based on this particular console.

\section{FUTURE RESEARCH}

This research has shown some initial interesting results that could be used in future research and since the mapping of the game controller is fairly easy to manipulate it therefore has become a good candidate for experimental manipulation. Similar experiments could be conducted to see the different advantages and shortcomings that different controllers provide and also to change the video game consol. By conducting experiments with the CD together with the difficulty and familiarity parameters, it could be possible to measure and find better mapping of game controllers according to the game genre and the need to conform to the players' natural mapping. This could be especially important and fruitful in game-based learning research in order to enhance games made for teaching something, e.g. for people with autism who perhaps have a different cognitive perception and therefore need special mapping of controller to be able to effectively learn through games. Other topics of interest to explore are: How will players define the level of familiarity of the game that is being given to them for the first time, based on their knowledge and expertise about controller complexity? How will a player then define the level of difficulty felt while playing a game? Most interestingly, how quickly or in what better ways will the player learn to play that game? These issues will be appealing to conduct in further research, which probably will result in a new paradigm of difficulty and familiarity of games. The concept of defining genres based on complexity is another issue. Together with controller complexity, a better way to learn games with a better defined familiarity and difficulty level might thus be possible.

\section{CONCLUSION}

Game control dimensionality is a fairly new concept which has not been explored in academic research as yet. Previous studies in game research have shown the importance of further understanding of difficulty and familiarity. We in this paper have made the initial attempt to show how controller dimensionality can be an important parameter to understand difficulty and familiarity in games. We have not as yet proposed any cognitive model that might guide designers to take any constructive approach for considering the results from this study, since this requires more investigation. Our analysis has shown that there are reasons to find relations between the foundations of game control dimensionality. Difficulty and familiarity are two parameters which we wanted to investigate with our measure of CD. Our results showed that both of these two parameters can reasonably be viewed from a new and different perspective. These interesting perspectives can lead towards contributing in the game design research for enhancing better learnability.

\section{ACKNOWLEDGMENTS}

Our sincere thanks to Dr Kent Norman for helping us with the data set which was coded by the students of the University of Maryland, as a part of a project of the Laboratory for Automation Psychology and Decision Process directed by Dr Norman.

\section{REFERENCES}

[1] A Timeline of NRL's Autonomous Systems Research. Retrieved 2014-05-12 from United States Naval Research Laboratory

http://www.nrl.navy.mil/lasr/documents/Autonomous_timeli ne.pdf

[2] Adams, E. 2008. The designer's notebook: Difficulty modes and dynamic difficulty adjustment. Retrieved 2014-05-14 from Gamasutra http://www.gamasutra.com/view/feature/132061/the_designe rs_notebook_php

[3] Aponte, M.V., Levieux, G., and Natkin, S. 2009. Scaling the Level of Difficulty in Single Player Video Games. In Proceedings of the 8th International Conference on Entertainment Computing (ICEC '09), Natkin, S. and Dupire, J. (eds.), Springer, Berlin, Heidelberg, 24-35. 
[4] Atari VCS (Atari 2600) - A Brief History of Game Console Warfare. Retrieved 2014-05-12 from BusinessWeek http://images.businessweek.com/ss/06/10/game_consoles/sou rce/3.htm

[5] Bateman, C. and Boon, R. 2005. 21st Century Game Design (Game Development Series). Charles River Media, Inc., Hingham, USA.

[6] Birk, M. and Mandryk, R.L. 2013. Control your game-self: effects of controller type on enjoyment, motivation, and personality in game. In Proceedings of the SIGCHI Conference on Human Factors in Computing Systems (CHI '13). ACM, New York, USA, 685-694.

[7] Bogost, I. 2009. Persuasive Games: Familiarity, Habituation, and Catchiness. Retrieved 2014-05-16 from Gamasutra http://www.gamasutra.com/view/feature/132369/persuasive_ games_familiarity_.php

[8] Boutros, D. 2008. Difficulty is difficult: Designing for hard modes in games. Retrieved 2014-05-14 from Gamasutra http://www.gamasutra.com/view/feature/132181/difficulty_is _difficult_designing_php

[9] Brown, E. and Cairns, P. 2012. A grounded investigation of game immersion. In CHI '04 Extended Abstracts on Human Factors in Computing Systems (CHI EA '04). ACM, New York, USA, 1297-1300.

[10] Calleja, G. 2011. In-Game: From Immersion to Incorporation. MIT Press, Cambridge, USA.

[11] Cox, A., Cairns, P., Shah, P., and Carroll, M. 2012. Not doing but thinking: the role of challenge in the gaming experience. In Proceedings of the SIGCHI Conference on Human Factors in Computing Systems (CHI '12). ACM, New York, USA, 79-88.

[12] Cummings, A.H. 2007. The Evolution of Game Controllers and Control Schemes and Their Effect on Their Games. In The 17th Annual University of Southampton Multimedia Systems Conference (MC07), Southampton, UK.

[13] Espinosa J.R.D. and Mares, P.R. 2012. Familiarity of challenges and optimal experience in movement interaction games. In Proceedings of the 4th Mexican Conference on Human-Computer Interaction (MexIHC '12). ACM, New York, USA, 47-50.

[14] Fullerton, T. 2008. Game Design Workshop: A Playcentric Approach to Creating Innovative Games. 2nd Ed. Morgan Kaufmann.

[15] Hunicke, R. 2005. The case for dynamic difficulty adjustment in games. In Proceedings of the 2005 ACM SIGCHI International Conference on Advances in computer entertainment technology (ACE '05). ACM, New York, USA. 429-433.

[16] Juul, J. 2003. The game, the player, the world: looking for a heart of gameness. In Proceedings of "Level Up" the 1st International Digital Games Research Conference (DIGRA) 2003, Copier M. and Raessens J. (eds.), Utrecht University, Utrecht. 30-45.

[17] Limperos, A.M., Schmierbach, M.G., Kegerise, A.D., and Dardis, F.E. 2011. Gaming Across Different Consoles: Exploring the Influence of Control Scheme on Game-Player
Enjoyment. Cyberpsychology, Behavior and Social Networking. 14(6). 345-350.

[18] Lu, W. 2003. Evolution of Video Game Controllers: How Simple Switches Lead to the Development of the Joystick and the Directional Pad. Retrieved 2014-05-12 from Stanford University http://web.stanford.edu/group/htgg/sts145papers/wlu_2003_ 1.pdf

[19] McEwan, M., Johnson, D., Wyeth, P., and Blackler, A. 2012. Videogame control device impact on the play experience. In Proceedings of the 8th Australasian Conference on Interactive Entertainment: Playing the System (IE '12). ACM, New York, USA, Article 18, 3 pages.

[20] McMahan, R.P., Alon, A.J.D., Lazem, S., Beaton, R.J., Machaj, D., Schaefer, M., Silva, M.G., Leal, A., Hagan, R., and Bowman, D.A. 2010. Evaluating natural interaction techniques in video games. In Proceedings of the 2010 IEEE Symposium on 3D User Interfaces (3DUI '10). IEEE Computer Society, Washington, USA. 11-14.

[21] Mustaquim, M. and Nyström, T. 2012. An Inclusive Framework for Developing Video Games for Learning. In Proceedings of the 6th European Conference on Games Based Learning (ECGBL 2012), Felice, P. (ed.), Academic Publishing International Limited, Reading, UK. 348-355.

[22] Norman, D.A. 1986. Cognitive engineering. In User Centered System Design: New Perspectives on HumanComputer Interaction, Norman D.A. and Draper S.W. (eds.), Lawrence Erlbaum, Hillsdale, USA. 31-61.

[23] Qin, H., Rau, P.L.P., and Salvendy, G. 2009. Measuring Player Immersion in the Computer Game Narrative. International Journal of Human-Computer Interaction, 25(2), 107-133.

[24] Romero, P. and Calvillo-Gamez. 2011. E. H. Towards an embodied view of flow. In Proceedings of the 2nd Workshop on User Models for Motivational Systems: The affective and the rational routes to persuasion (UMMS 2011), Girona, Spain.

[25] Skalski, P., Tamborini, R., Shelton, A., Buncher, M., and Lindmark, P. 2011. Mapping the road to fun: Natural video game controllers, presence, and game enjoyment. New Media \& Society. 13(2). 224-242.

[26] Swain, C. 2008. Master Metrics 2.0: Using Metrics-based Design Techniques to Craft Better Play Experiences. Paper Presented on the Game Developer Conference 2008, San Francisco, USA.

[27] Swain, C. 2008. Master Metrics: The Science Behind the Art of Game Design. In Game Usability - Advancing the Player Experience, Isbister, K. and Schaffer, N. (eds.), Morgan Kaufman. 119-140.

[28] Takahashi, D. 2002. Opening the Xbox: Inside Microsoft's Plan to Unleash an Entertainment Revolution. Prima Communications, Inc., Roseville, USA.

[29] Youssef, A. and Cossell, S. 2009. Thoughts on adjusting perceived difficulty in games. In Proceedings of the Sixth Australasian Conference on Interactive Entertainment (IE '09). ACM, New York, USA. Article 14, 4 pages. 